\title{
Organ Preservation: Cryobiology and Beyond
}

\author{
Erik J. Woods ${ }^{1,2} \cdot$ Steven F. Mullen ${ }^{1}$
}

Published online: 5 April 2016

(C) Springer International Publishing AG 2016

\begin{abstract}
Advances in surgical techniques, immunology, and organ donor networking have allowed organ transplantation to evolve over the last several decades into a procedure that has saved hundreds of thousands of lives. While these dramatic advances have made organ transplantation more effective, they have also highlighted the growing shortage of donor organs. Unfortunately, many organs that could be of potential use for transplantation end up discarded due to short preservation times, often only 4-12 h for vital organs. Organ preservation systems have been investigated with renewed vigor in attempts to solve this problem, and new tools are becoming available that make solutions much more possible than ever before. The cryobiology of organs must be understood for long-term banking solutions to be feasible, combined with greater understanding of the physio-chemical processes that take place during ischemia and reperfusion. New approaches based on natural models, stem cells, and various novel proteins and trophic factors all show great promise in accomplishing the goal of more donor organs matched with more patients in need.
\end{abstract}

Keywords Cryopreservation · Organ banking ·

Transplantation · MSCs · Trophic factors · Gene therapy

This article is part of the Topical Collection on Artificial Tissues

Erik J. Woods

Erik.Woods@CookRegentec.com

Cook Regentec, 1102 Indiana Avenue, Indianapolis, IN 46202, USA

2 Indiana University School of Medicine, Indianapolis, IN, USA

\section{Introduction}

According to statistics from the Organ Procurement and Transplantation Network (http://optn.transplant.hrsa.gov/), at the time of this writing (December 6, 2015), 78,833 individuals are currently listed as active donor organ waiting list candidates in the USA. Roughly $95 \%$ of the demand is for kidney and liver transplants. Unfortunately, it is expected that only approximately 30,000 individuals will have received organ transplants in 2015, and 22 people die each day due to the lack of available organs for donation. These data highlight the gap between need and availability of donor organs.

Despite the continued need for organ availability, survivorship after transplantation is quite high, with $\geq 75 \%$ of those receiving kidney, heart, and liver transplants living more than 5 years after the transplantation surgery.

There are a number of logistical issues associated with organ transplantation, all of which contribute to the challenge of improving the outcomes for those waiting for transplants.

It is unlikely that perfect equity in regards to distribution of available organs will ever be achieved, despite the best efforts of organizations in this particular area. One significant reason for this is the finite time for which organs remain viable after the onset of ischemia, often measured in hours, not days. As a result, in order for the best outcomes to be achieved, the transplant must take place as quickly as possible after organ procurement. For example, in one study, it was reported that twice the number of organs showed signs of change when transported to a different facility from where the procurement took place compared to those having been transplanted at the same facility [1].

The heart and lung have the shortest viable lifespan during ischemic cold storage, with viability dropping off after $\sim 4$ and 6-8 h, respectively [2]. Kidneys, on the other hand, tolerate cold ischemia better, and it is considered acceptable to 
transplant kidneys within $18 \mathrm{~h}$ of procurement. The liver and pancreas fall between these two values, with ideal transplantation times being within $12 \mathrm{~h}$ of procurement. For organs having been donated after circulatory death of the donor individual, these numbers are reduced.

Significant advances in preservation have occurred over the previous decades, allowing extension of the viable time frame between organ procurement and transplantation. This has been due to the development of cold preservation solutions and means of their application. An excellent review of the background describing the biochemical changes associated with ischemic, hypoxic, and hypothermic injury and the associated reasoning behind the formulation of these types of solutions has recently been published [3]. A brief review of organ damage due to transplantation is discussed below.

\section{Transplantation and Organ Damage}

\section{Ischemia and Hypothermic Injury}

Since the early days of organ transplantation, people have studied the consequences of temporary and long-term storage of organs to facilitate the procedure. Over the years, this has resulted in many advances in our understanding of the pathophysiology of what has become to be known as ischemia/ reperfusion (I/R) injury. The greater understanding of these consequences and their mechanisms create promising possibilities for reducing sources of injury during organ preservation and transplantation, as has opened opportunities for other strategies as well, such as tissue preconditioning to tolerate I/R and methods to repair injured tissues directly after the fact. Organs can be injured beyond repair in response to both ischemia and, paradoxically, restoration of blood flow [4•]. I/R injury is especially relevant to complex tissue allografts (CTAs) such as vascularized tissues or organs. Ischemia describes deficient blood supply and has been used to describe the process since the early nineteenth century. Since first understanding the effect it had on organs, researchers have endeavored to understand its underlying mechanisms [4•].

Organ ischemia can be divided into two phases. The first is warm ischemia, in which an organ may be exposed to relatively high temperatures immediately following disruption of circulation until the organ can be flushed with a cold, hypothermic preservation solution. The second phase, cold ischemia, occurs when the organ is maintained in a hypothermic state prior to transplantation into the recipient $[5,6]$. In multiorgan recovery, the organs are typically cooled before they are removed.

Cooling is indeed the best defense against ischemic injury; however, lowering the temperature of a biological system wreaks havoc on many fundamentally important structural and functional aspects. For instance, the cellular membrane plays a structural role and provides an active interface with the extracellular environment. Proteins responsible for cell signaling, ion regulation, and other important processes are integrally linked to the cellular membrane and essential to cellular function. The ability of the membrane to protect the cell from ionic and molecular permeability (including water permeability) depends on the integrity of the lipid bilayer and on its ability to maintain tight control of these parameters [5]. Low temperature can result in a membrane phase transition of lipids and can drastically affect cellular stability. Low temperature can also impair membrane-bound enzymes crucial for maintaining cellular homeostasis. Membrane changes caused by such phase transitions are known to cause increases in membrane permeability. If normally non-permeable species enter the cell during the phase transition, they become trapped upon return to ambient or body temperature. The result of this is cell swelling when water rushes into the intracellular space to balance the chemical disequilibrium, which causes cell swelling and potentially lysis. This can be mitigated by adding benign non-permeating solutes to organ preservation solutions $[5,6]$.

During ischemia, excessive production of hydrogen ions occurs as the cell is forced into anaerobic metabolism. This results in a lack of adenosine triphosphate (ATP) and a resulting impairment of the sodium-potassium adenosine triphosphatase (Na-K ATPase) pump. Impairment of this pump, which functions to maintain the ionic composition of the cell, causes potassium to move out of the intracellular space through osmotic diffusion, and sodium, which is normally found in relatively low concentrations inside the cell, to diffuse in. As described above, this change in intracellular ionic composition can cause swelling and potentially cell lysis. To mitigate this effect of hypothermic ischemia, use of preservation solutions with electrolyte compositions similar to the intracellular composition (e.g., high potassium and low sodium) is often employed and allows the cell to rest in a state of inactive homeostasis $[5,6]$.

Hydrogen-ion production increases in ischemic organs causing intracellular $\mathrm{pH}$ to decrease. In the liver especially, where the switch from aerobic to anaerobic glycolysis occurs during ischemia and results in increasing production of lactic acid, this type of injury is particularly problematic. Additionally, the membrane permeability of calcium is increased during ischemia. As this occurs, influx of calcium can lead to intracellular acidosis. Calmodulin, which senses these high calcium levels, relays signals to various calciumsensitive enzymes which, in turn, cause upregulation of phospholipases. This can lead to mitochondrial membrane permeability and subsequent dysfunction. Increased cellular calcium concentrations also initiate myofibrillar contraction of the vascular smooth muscle, causing vasospasm and subsequent ischemic damage [5-7]. Endothelin, a 21-amino acid peptide produced by the vascular endothelium, can exacerbate 
ischemic vasoconstriction and can therefore worsen ventricular, coronary, and other organ function upon reperfusion $[8,9]$. Endothelin A and B receptor antagonists have been evaluated successfully to improve results after solid organ transplantation [6].

Hypothermia also decreases the metabolic rate and slows degradation of cellular components, but even at low (above freezing) temperatures, metabolism is not completely suppressed. Aerobic cells function based on a combination of the anaerobic enzymatic breakdown of glucose (glycolysis) and aerobic cellular respiration. Cooling from 37 to $0{ }^{\circ} \mathrm{C}$ reduces cellular metabolism 12-fold [5]. Because of this, even though metabolism and utilization of cellular energy stores are slowed, ATP and adenosine diphosphate (ADP), the major sources of cellular metabolic energy, are gradually depleted during hypothermia. This depletion is a result of the residual energy requirements of the cell at low temperature still exceeding the amount of ATP able to be produced by the cell. During organ ischemia, anaerobic gycolysis results in lactate production and impairment of mitochondrial respiration. This ischemic mitochondrial dysfunction is responsible for most of the damage due to cellular energy disruption, and overall reduction of mitochndrial enzyme activity and/or mitochondrial alteration has been associated with apoptotic pathways $[6,7$, $10,11]$. Recent studies evaluating mitochondrial-targeted antioxidants show promise in mitigating this type of damage [7].

\section{Reperfusion Injury}

Paradoxically, the major injures to transplanted organs occur during reperfusion as opposed to ischemia. In addition to frank injury, some of the events that occur during reperfusion may result in enhanced immunogenicity of the graft [12]. These findings have led to many advances in organ preservation aimed at preventing reperfusion injury. Oxygen free radicals generated during reperfusion are arguably the main cause of the reperfusion injury, acting through various mechanisms $[12,13]$. While an organ experiences ischemia, increased calcium levels can activate specific intracellular enzymes that convert xanthine dehydrogenase to xanthine oxidase [12]. Both these enzymes catabolize hypoxanthine and xanthine to uric acid. In the case of xanthine oxidase, molecular oxygen is used as an electron acceptor which results in formation of superoxide [12]. Superoxide rapidly forms hydrogen peroxide, which is a strong oxidant that can cause cell injury or death by oxidizing lipid membranes and cellular proteins directly, and produces many other reactive oxygen species, including hydroxyl radical and singlet oxygen. Oxygen free radicals form very quickly, and the damaging effects on the organ begin almost immediately upon reperfusion $[5,6]$.

Additionally, when an organ is exposed to ischemia, oxygen levels become too low for xanthine oxidase to metabolize xanthine and hypoxanthine, causing a buildup in the intracellular concentration of these metabolites. Upon reperfusion when oxygen is once again available, cellular systems proceed and the backlog of metabolism results in a sudden production of reactive oxygen intermediates. This overwhelms the cellular pathways responsible for scavenging reactive oxygen species and results in cellular injury. Inhibitors of xanthine oxidase such as allopurinol have been shown to protect against this type of ischemic injury when applied prior to the insult [6].

Reactive oxygen species can also result in lipid peroxidation [13]. During lipid peroxidation, oxygen free radicals interact with polyunsaturated fatty acids in the cellular membrane resulting in a chain reaction that may ultimately destroy cellular integrity and thus kill the cell. Glutathione, an endogenous free radical scavenger, can reduce lipid peroxidation and is used along with other similar agents in organ preservation solutions to mitigate reperfusion injury [13].

Oxygen free radicals can also directly activate phospholipase A201 which can in turn initiate production of prostaglandins such as leukotriene B4. This specific prostaglandin is a chemokine that causes leukocytes to adhere to the vascular endothelium, which can result in degranulation causing proteolytic damage and/or blocking of microcirculation $[6,7]$.

In addition to reactive oxygen species, cytokines and nitric oxide also play a significant role in reperfusion injury. Cytokines are intercellular messengers that are produced both during normal as well as pathophysiologic states. Ischemia/ reperfusion injury results in a dramatic increase of several such cytokines, including tumor necrosis factor (TNF)-alpha, interferon-gamma, interleukin-1, and interleukin-8 [14]. Increased production of these cytokines results in upregulation of adhesion molecules that can cause leukocyte adherence and platelet plugging following revascularization, which can result in graft failure and/or rejection. Likewise, nitric oxide (NO) has been correlated with acute rejection [15]. An extremely reactive autocoid, NO is generated by nitric oxide synthase from L-arginine. Reports indicate that NO production is induced by inflammatory cytokines, such as TNF-alpha, interferon-gamma, and interleukin-1.

\section{Challenges with Long-Term Preservation of Organs}

While the time frames for which organs can be preserved outside of the normal physiological environment have been extended as mentioned above, it is likely that the only means to optimize the utility of organs for donation would be to preserve them in a manner that eliminates deterioration on any meaningful time scale. The use of cooling to slow down metabolism and reduce the injury associated with the lack of adequate energy supplies can be extrapolated in such a manner that all forms of degradation can be stopped. Theoretically, this could be achieved with the use of cryopreservation, as is 
commonly done with isolated cells and small tissue fragments on a routine basis.

A number of challenges exist with the cryopreservation of large pieces of tissue on the scale of whole organs [16], some of which are similar to the challenges with cryopreserving any biological cell [17] and others that scale with the size of the material.

Since the publication in 1949 of the serendipitous discovery of the cryoprotective effects of glycerol on spermatozoa, it has been understood that, with very few exceptions, the use of intracellular cryoprotective compounds is necessary to preserve cells from the injurious effects of freezing. While we still have an incomplete understanding of the extent of their modes of action, we are aware of a few means by which they help to improve the viability of cells after their use [18-20].

One of the earliest hypotheses tested was that they have a colligative effect and reduce the concentration of salt that develops when water precipitates from the frozen solution as ice [21]. By adding a compound to the solution prior to freezing, the concentration of salt attained at any given temperature is reduced. The correlation of salt concentration and cell damage, both in the presence of ice and its absence, was remarkable. However, Meryman countered this argument by proposing that it is not the attainment of a high salt concentration per se that causes the damage but the reduction in cell volume that results from the hypertonic environment [22].

In a similar fashion, the addition of cryoprotective molecules increases the total volume of the unfrozen fraction of a solution at any given temperature and also reduces the minimum volume attained by a cell during freeze-induced dehydration. This effect has also been proposed as the reason for the colligative protection by these molecules when used during freezing [22].

It has been suggested that some molecules with cryoprotective properties are able to stabilize macromolecular structure in a reduced liquid water environment by preferentially being excluded from the surface, rendering the surface more hydrated that it otherwise would be in the absence of the molecules [23, 24]. In essence, this reduced the dehydrating effect of the concentrated solution to which the molecules are exposed.

From the early days of cryobiology, ice formation was hypothesized to be a major contributor to cell damage. The chemical effects of ice formation were alluded to above, as the chemical composition of the unfrozen fraction increases due to ice formation. Cells that start off suspended in the solution are sequestered in the unfrozen fraction and are directly exposed to this freeze-concentrated solution. This produces a chemical potential gradient between the intracellular and extracellular solutions, resulting in the exosmosis of cellular water, in an effort to restore chemical potential equilibrium. The result of this is an increase in solute concentration and a decrease in cell volume, which as mentioned have both been proposed to be significant contributors to cell damage.
Cellular damage directly from ice crystals has also been proposed. Mechanical forces from growing ice crystals are thought to play a role in damage when the ice forms inside of cells as well as outside $[25,26]$ and also outside of cells in organized tissue $[27,28]$ - the later effect being of particular importance for the current discussion. Other proposals to explain the damaging effects of intracellular ice include intracellular osmotic damage/dilution shock [29], protein denaturation [30, 31], and gas bubble formation [26].

All of the hypothesized mechanisms of cellular damage resulting from attempts at cryopreservation are expected to affect organs as well. The complications arising from trying to optimize cellular preservation are exacerbated by one or more orders of magnitude simply due to the size of the organs that are targets for preservation. Typical isolated cells have a diameter on the order of $5-10 \mu \mathrm{m}$, whereas the sizes of organs are measured in centimeters. This presents challenges when it comes to the introduction and removal of cryoprotectants as well as the removal and introduction of heat during the process of preservation.

\section{Heat and Mass Transfer During Organ Cryopreservation}

As for isolated cells, it will be necessary to prevent damaging levels of intracellular ice formation in cells within a tissue, as well as within the intercellular spaces. The primary means to accomplish this is by increasing the solute concentration of these compartments by either freeze dehydration or initially loading vitrifiable concentrations of cryoprotectants into the tissue. For an elaboration on the latter approach, see below.

While it can take up to several minutes to safely load isolated cells with cryoprotectants during a freezing procedure, the luxury of direct exposure when bathed in a cryoprotectant solution and short diffusion distances from the outside to the inside are not available for cells within an organ. The time required for diffusion to occur scales with the square of the diffusion distance. This challenge is best illustrated by example. The time necessary for a protein molecule to diffuse into the center of a cell is on the order of seconds and to diffuse across a thin piece of tissue $(2 \mathrm{~mm})$ is in the order of $27 \mathrm{~h} \mathrm{[32].}$ Hence, simply placing an isolated organ into a bath containing cryoprotectants will not suffice to load these molecules into the cells for preservation. As a result, procedures for the cryopreservation of organs usually rely upon perfusing the organ's vasculature with cryoprotectants to significantly reduce the distance necessary for these compounds to travel in order to protect the cells on the interior of the structure.

A similar problem occurs with the need to dehydrate the cells prior to storage at cryogenic temperatures. In a freezing method, one relies upon the water to diffuse out of the cells and precipitate in the extracellular space in order to protect the 
intact cell from the damaging effects of intracellular ice formation. The same problem of scale exists as described above, although for a small molecule like water, the diffusion will take place faster. However, ice formation outside of the cells is not innocuous in a tissue, as has been shown by several investigators [27, 33-37]. Even with well-intentioned attempts to prevent intracellular ice formation, gradients of cryoprotectant concentrations and osmotic imbalances across a tissue can result in varying levels of stress and post-thaw viability across a tissue [38, 39] (see discussion in [40]), resulting in damage associated with cryoprotectant toxicity and excessive osmotic stress.

Problems associated with heat transfer are analogous to that of mass transfer as just described. Thermal gradients will be established when freezing a bulk solution containing an organ as a result of the heat sink being located on the outside of the vessel, and the necessity for heat to diffuse out of the organ and into this sink. The success of freezing isolated cells as measured by post-thaw viability is known to be strongly dependent upon cooling rate, and this is likely to be similar for cells within the confines of a tissue. Hence, thermal gradients and associated freezing rates may be deleterious to cells located within an organ during a cryopreservation procedure.

Thermal gradients and associated thermomechanical stress issues are exacerbated in larger systems [41, 42]. This type of stress can actually lead to fracturing of frozen and vitrified solutions, causing significant structural damage to the biomaterial contained within $[43,44]$. A relatively simple method to avoid fracturing is to reduce the cooling and warming rates, which reduces the degree to which thermal gradients develop in the system $[45,46]$. However, this may result in other changes, such as prolonged exposure to cryoprotectant solutions, and should be used in conjunction with other approaches to optimize a cryopreservation procedure.

It has also been shown that, at least under some conditions, extracellular ice forms preferentially in the vasculature [47]. This is an obvious concern when trying to preserve organs with the goal of transplantation and anastomosis.

Many of the problems associated with freezing organs could, at least in theory, be prevented by the total elimination of ice formation in the sample [48]. Vitrification, as this approach is called, is not a new concept but has its roots in ideas dating back to the 1930s [49], with Luyet developing an extensive research program in vitrification during this time [50, 51]. Contrary to some of Luyet's work as well as that of modern embryologists [52], organ vitrification cannot be accomplished using ultra-rapid methods of cooling and warming. It is still possible to vitrify a solution as large as a whole organ, however, given that the solution used for vitrification is designed for this purpose [53-56]. Furthermore, avoidance of fractures in vitrified samples can be achieved as described above.
This is not to suggest that developing a successful vitrification procedure for whole organs is simple and straightforward. On the contrary, to vitrify at a slow rate of cooling and warming requires solute concentrations on the order of $8 \mathrm{~mol} / \mathrm{L}$ and a means to introduce the cells to that solution without lethal consequences. Significant research efforts have gone into improving the vitrification solutions and their application used for vitrifying various systems [57-66], and the results of these studies suggest that we are approaching the goal of the successful vitrification of some types of organs [67].

\section{New Approaches}

\section{Insight from Nature and Molecular/Genetic Mechanisms}

Many mammalian animal systems (such as hibernatory mammals) have become adapted to cold exposure, allowing them to thrive in extremely cold regions where they would otherwise not be able to survive. Nature has evolved several key mechanisms that enable hypothermic and hypoxic survival in animals. Of these mechanisms, the ones that can potentially be most useful for organ preservation include (i) ability to suppress global metabolic rate, (ii) metabolic pathways capable of sustaining and/or delivering minimal essential energy during hypoxia and/hypothermia, and (iii) molecular and cellular defense mechanisms that allow normal metabolism to return upon arousal $[68 \cdot \bullet]$. Many of these are conserved across animal phyla, which may be why human organs can be cooled to some extent with minimal impact on physiological functionality [68••]. However, even if human organs have some of these cold-tolerant genes, they do not necessarily have the capacity to access and apply them, which is why human organs can only tolerate cooling for limited time periods.

Some amphibian and reptile species that live in seasonally cold climates have also developed the ability to survive longterm freezing with about two thirds of their body water frozen as extracellular ice [69]. Surviving this frozen state requires a symphony of responses by cells and organs to sustain homeostasis and allow physiological reconstitution upon warming. This includes directing energy toward the most efficient cellular processes to maintain viability and protection of macromolecules (beyond metabolic production of cryoprotectants, e.g., antioxidant defenses). In this way, freeze tolerance is similar to hypoxia and dehydration, which are also commonly encountered environmental stresses. Freeze/thaw-responsive control of gene expression is now a very active area of research. This epigenetic control of gene expression is likely allowing for anoxia tolerance as well as metabolic suppression and creates unique patterns of freeze-responsive gene and protein expression. This has now been documented via traditional methods, such as signaling pathways impacting 
transcriptional factors, and also via post-transcriptional regulation of messenger RNA (mRNA) transcripts by small noncoding RNA species that influence the fate of mRNA (microRNAs) [70-74, 75••].

Understanding of the natural mechanisms of animal cold hardiness, hypoxic tolerance, and dehydration is not only key to understanding the principles and mechanisms by which organisms survive cooling to freezing temperatures and rewarming; it may also enable breakthroughs in the banking of human organs and other CVAs. Evidence supports that many of the mechanisms used by these cold-tolerant animals are conserved in hibernating mammals and even primates, with some evidence that analogous mechanisms are found in humans as well [75••].

The few molecular studies of gene expression targeting organ transplant specifically have largely targeted reperfusion injury [76]. These studies have focused on the role of certain signaling pathways such Bcl-2 and Bag-1, two regulatory genes controlling apoptosis to reduce cell damage through hypoxia [77]. There is also a possible effect on the heme oxygenase-1 (HO-1) pathway (a stress protein induced in response to oxidative challenges) [78] and on the hypoxiainducible factor (HIF) pathway that responds to challenges in available oxygen [79]. Gene therapy has also been proposed as an option to recondition donor lungs ex vivo. Human lungs transfected for IL-10 expression exhibited improved functional quality, increased oxygenation, decreased vascular resistance, improved cell-cell interaction, and a positive shift from a proinflammatory to an antiinflammatory cytokine release.

Proteomic technology in conjunction with enhanced understanding of the epigenetics involved is now allowing identification of proteins related in cellular adaptation in response to $\mathrm{I} / \mathrm{R}$ injury and has begun to allow investigation into whether these molecular clues might explain the phenotypic changes expressed in the cells [80].

Many obstacles remain before these studies can be translated into clinical application. With advances in gene therapy, there is promise that such obstacles may be overcome; however, improved methods for vector transfer and delivery protocols (without toxicity) and the timing of gene induction (among many other details) will need to be developed to fully integrate the two fields [76].

\section{Mesenchymal Stem Cells and Organ Preservation}

Adult-derived stem cells such as mesenchymal stem cells (MSCs) offer great therapeutic promise for numerous clinical applications. They can be derived from virtually any tissue in the body that heals, including bone marrow, blood, adipose, dental pulp, umbilical cord/placenta, liver, pancreas, and brain [81]. To date, MSCs originating in bone marrow have arguably been the most extensively studied and are the first cells to be used successfully in therapy [82]. Commonly described as "mesenchymal stem cells" or "mesenchymal stromal cells" (MSCs), these cells have been shown to possess multipotentiality when induced ex vivo. When isolated by adherence to plastic and expanded ex vivo, these cells demonstrate the ability to differentiate into a broad range of cell types of mesodermal origin, including osteoblasts, adipocytes, and chondrocytes, and to some extent ectodermal (neuronal) and endodermal (hepatocytes) origins [83]. In addition to their ability to differentiate into mesodermal tissues, MSCs secrete a variety of cytokines and growth factors that have very potent paracrine activity, distinct from the direct differentiation of MSCs into tissue. These secreted bioactive factors suppress the local immune system, inhibit fibrosis (scar formation) and apoptosis, enhance angiogenesis, and stimulate mitosis and differentiation of tissue-intrinsic reparative or stem cells. Several studies have tested the use of MSCs in models of cardiac damage (infarct), brain damage (stroke), and meniscal regeneration focusing on such paracrine influence (MSCmediated trophic effects) as the means of tissue repair [84].

In renal studies, intravenously administrated MSCs have been shown to home to ischemic tubular sites and can be detected within the first hour after cell infusion [85, 86]. The exact process of MSC migration and recruitment is still under debate [87]; however, it is thought to be caused by migration down a gradient of stromal cell-derived factor-1 (SDF-1, a chemokine protein) induced by proinflammatory stimuli followed by adhesion to molecules generated and expressed by injured tissue [86, 88, 89]. Cell-fate and cell-tracking studies have provided support for this theory by demonstrating that MSCs administered exogenously are transiently present at the injury site before being cleared from the circulation [90]. It has also been demonstrated that MSCs are able to actively transmigrate into inflamed tissue across TNF- $\alpha$-activated endothelium and become partially integrated in the endothelial layer [91].

MSCs can provide benefit during both ischemia and reperfusion to support the repair of damaged tissue [92•]. MSCs release potent growth factors such as vascular endothelial growth factor (VEGF), insulin-like growth factor (IGF), hepatocyte growth factor (HGF), keratinocyte growth factor (KGF), monocyte chemoattractant protein-1 (MCP-1), SDF1 , and fibroblast growth factor (FGF). These factors stimulate endogenous cellular repair mechanisms, including stimulation of proliferation and angiogenesis [93-98]. In response to inflammation, it has been demonstrated that MSCs modulate or alter inflammatory responses and release immune-mediators, such as IL-10, IL-6, TGF-b, prostaglandin E2 (PGE2), NO, and IDO and generate a local antiinflammatory proreparative cellular state $[99,100]$. In addition to their antiinflammatory actions, MSCs may induce regulatory T cell expansion [101, 102] which could mitigate allogeneic organ rejection as well as provide support against $\mathrm{I} / \mathrm{R}$ injury. It has also recently been 
shown that administration of MSCs promotes macrophages to shift toward the antiinflammatory M2 phenotype, as characterized by expression of a mannose receptor (CD206) and a distinct cytokine profile, consisting of high levels of IL-10 and IL-6 and low levels of IL-12 and TNF-a [92•, 103-105].

Intravenous infusion of MSCs for acute renal injury has been demonstrated to result in accelerated tubular repair and improved kidney function [92•]. In a rat model, clamping of the renal pedicles followed by intraaortic infusion of MSCs resulted in enhanced organ function and resulted in fewer apoptotic cells as compared to vehicle-only treated controls [86]. More recently, MSCs were also shown to stimulate tubular cell proliferation, reduce acute tubular necrosis, and suppress oxidative stress and proinflammatory responses [106-108] or hinder the progression of fibrosis [109, 110]. Other studies have focused on further enhancing the MSC secretome to benefit organ transplantation, including human umbilical cord-derived MSCs designed to overexpress HGF (demonstrated in a rat I/R model [111]) or BMP-7-transduced MSCs (demonstrated in a rabbit model [112]) [89, 113-115]. In rat kidney transplantation studies, MSCs showed promising results and demonstrated less cold ischemia-induced inflammation in early acute allograft rejection [116] as well as longterm benefit in a chronic allograft nephropathy model [117]

Intravenous infusion of MSCs in endotoxin-induced lung injury models resulted in decreased proinflammatory cytokines, increased antiinflammatory cytokines, and higher survival rates [118-122]. Additionally, utilizing a gene therapy approach to modify MSCs to deliver IL-10 resulted in reduced signs of injury, lower numbers of apoptotic cells, and less immune cell infiltration in a rat model of lung I/R injury [123].

Human clinical trials utilizing MSCs to enhance human solid organ transplantation have begun, with several trials registered with the US FDA on clinicaltrials.gov. A phase II trial which has finished (\#NCT00658073) compared autologous MSC-based cell therapy to traditional anti-IL-2 receptor antibody induction therapy in patients undergoing renal transplantation and demonstrated lower incidences of acute rejection and decreased risk of opportunistic infection in the MSCtreated group [124]. Another similar phase I/II trial (\#NCT00734396), which has also completed, evaluated the safety and feasibility of autologous mesenchymal stem cell therapy in HLA-DR mismatched kidney transplant patients with subclinical rejection (SCR) and or an increase in interstitial fibrosis/tubular atrophy (IF/TA) in the renal biopsy 4 weeks or 6 months after renal transplantation. In that study, the autologous BM MSCs were determined to be clinically feasible and safe, and the findings were suggestive of systemic immunosuppression [125]. Another completed phase II clinical trial utilized human umbilical cord-derived Wharton's jelly as the source of MSCs (\#NCT01291329) and investigated intracoronary injection of the MSCs for cardiac regeneration in patients with acute myocardial infarction. Other combined phase I/II clinical trials utilizing intramyocardial administration of autologous bone marrow-derived MSCs to treat severe chronic myocardial ischemia or chronic ischemic ventricular dysfunction secondary to myocardial infarction (\#NCT00587990 and \#NCT00260338) have also now completed [92•]. As more clinical trials are completed and published, a deeper understanding of the therapeutic potential of MSCs will be gained; however, it cannot be denied that the potential for MSCs to ameliorate myocardial ischemia could have profound benefit on organ preservation.

\section{Novel Trophic Factors for I/R Injury}

Over the last decade, renewed emphasis has been placed on trophic factors as a means to avoid or mitigate organ damage during transplantation, resulting in a number of very important studies. McNaulty et al. (2002) [126] examined the effect of trophic factor supplementation of University of Wisconsin (UW) solution on cold storage of canine kidneys. In that study, bovine neutrophil peptid-1 (bactenecin), substance P, nerve grown factor, epidermal growth factor, and insulin-like growth factor-1 were all added to UW lactobionate solution, and kidneys were stored for up to 4 days [126]. Dogs transplanted with kidneys stored in the supplemented solution had significantly lower peak serum creatinine values and returned to normal faster than kidneys stored for only 3 days in unmodified solutions.

Importantly, while some of the factors used in McNaulty's study, such as IGF-1 and EGF, have the potential to exert beneficial effects by affecting mechanisms of reperfusion injury [127-129], this was the first study in which it was conclusively demonstrated that using trophic factors only during ex vivo cold storage could substantially suppress cold ischemic injury. Treating organs in this way resulted in dramatic and immediate effects on function following transplantation [126]. Their results supported the hypothesis that the reduction of available trophic factors due to suppressed metabolism under cold ischemia results in cold ischemic injury during hypothermic preservation using synthetic cold-storage solutions and underscores the potential effect these factors can exert. It was also the first study to demonstrate consistently successful preservation of kidneys for up to 6 days without the use of perfusion technologies. This study showed that trophic factors appear to exert biologic effect in tissues even at low temperatures [130]; however, the mechanism of the influence these factors have on cellular activity during cold storage remains unclear. Previous studies have shown that trophic factors and cell signaling pathways can have significant activity at temperatures as low as $0{ }^{\circ} \mathrm{C}[131]$. However, certain pathways and cascades may have discrete steps that are cold sensitive and shut down at low temperature, and although the overall pathway may be activated in the cold, the actual effector mechanisms may not be realized until the cells are 
Table 1 Transplantation and organ damage: some mechanisms and potential solutions for two main phases of damage

\begin{tabular}{|c|c|}
\hline \multicolumn{2}{|c|}{ Phase of damage: ischemia and hypothermic injury } \\
\hline Mechanism of damage & Potential solutions \\
\hline Warm ischemia & Cooling the system to refrigerated temperature to reduce metabolism \\
\hline \multirow[t]{3}{*}{ Cold ischemia } & Hypothermic preservation solutions \\
\hline & -Intracellular-like solutions to maintain ionic homeostasis \\
\hline & -Hypertonic solutions to prevent cell swelling \\
\hline \multirow[t]{2}{*}{ Ischemic mitochondrial dysfunction } & Mitochondria targeted antioxidants \\
\hline & -MitoQ \\
\hline \multicolumn{2}{|l|}{ Phase of damage: reperfusion injury } \\
\hline Mechanism of damage & Potential solutions \\
\hline \multirow[t]{3}{*}{ Oxygen free radical damage } & Antioxidants \\
\hline & -Glutathione \\
\hline & Xanthine oxidase inhibitors \\
\hline \multirow[t]{2}{*}{ Enhanced immunogenicity } & Reduction of proinflammatory cytokines \\
\hline & -Immune modulatory cells (MSCs) or cell-secreted factors \\
\hline
\end{tabular}

rewarmed. Additionally, expression of mRNA for various trophic factors and peptides, such as vascular endothelial growth factor [132] and endothelin [9], can be increased during cold storage, while their corresponding receptors may be concurrently downregulated, yielding no net increase in effect. In studies investigating hypothermic storage of lamb cerebral and coronary arteries, the low temperature appeared to increase tyrosine kinase phosphorylation of proteins [133, 134]. These studies support the theory that many cell signaling pathways remain active even at low temperatures and can still be affected by trophic factors [126]. Exactly how these factors affect cell metabolism under hypothermic conditions and how they may buffer reperfusion injury still remain to be determined.

Recent studies have demonstrated that conditioned media from bone marrow MSCs containing trophic factors and microvesicles (MSC-MVs) administered immediately after induction of $\mathrm{I} / \mathrm{R}$ reverses acute kidney injury (AKI) and protects against chronic kidney disease (CKD) $[135,136]$. MSC-MVs are reported to contribute to the observed regenerative effects of MSCs in I/R injury by transferring RNA and providing ATP through mitochondrial transfer to ischemic tissue [92•]. This restoration of energy supply mediated by MSC-MVs is crucial to drive repair of ischemia-damaged tissues and may account for the beneficial effects of administration of MSCs in early stage I/R injury [92•]. Prosurvival gene activation has also been demonstrated through MSC-MVs. In a study by Bruno et al. [137], MSC-MVs were shown to induce the prosurvival genes (Bcl-xL, Bcl2, and BIRC8) and downregulate proapoptotic genes like Casp1, Casp8, and LTA.

The effects of MSC conditioned media (MSC-CM) trophic factors were shown to be associated with a
Table 2 Challenges and potential solutions with the long-term preservation of organs

\begin{tabular}{ll}
\hline Current challenges & Potential solutions \\
\hline Exposure to increased salt concentration & $\begin{array}{c}\text { Use higher concentrations of permeable cryoprotectants, } \\
\text { including sufficiently high to achieve vitrification } \\
\text { Increase the concentration of permeable cryoprotectants } \\
\text { used and perform multistep addition and removal }\end{array}$ \\
Changes in cell volume & $\begin{array}{l}\text { Utilize permeable and non-permeable cryoprotectants that } \\
\text { counter this effect }\end{array}$ \\
$\begin{array}{l}\text { Removal of bound water at the surface of } \\
\text { macromolecules }\end{array}$ & $\begin{array}{l}\text { Slow the rate of cooling, or use vitrification methods } \\
\text { Damage from intracellular ice formation }\end{array}$ \\
$\begin{array}{l}\text { Utilize vitrification methods } \\
\text { Loading with sufficient cryoprotectant } \\
\text { Limits on cooling and warming rates }\end{array}$ & $\begin{array}{l}\text { Perfuse the CPA through the vasculature } \\
\text { Design cryopreservation solutions to match the available } \\
\text { rates }\end{array}$ \\
Creation of thermal gradients and the \\
consequent buildup of thermomechanical \\
stress
\end{tabular}$\quad$\begin{tabular}{l} 
Reduce the rates of cooling and warming \\
\hline
\end{tabular}


Table 3 Highlights of some current advances in complex tissue preservation

\begin{tabular}{|c|c|}
\hline Advancement & Reference \\
\hline Vitrification of rabbit kidney and successful transplantation & $\begin{array}{l}\text { https://www.ncbi.nlm.nih.gov/pmc/ } \\
\text { articles/PMC2781097/ }\end{array}$ \\
\hline $\begin{array}{l}\text { 21-h preservation of transplanted rat hearts using antifreeze } \\
\text { proteins }\end{array}$ & $\begin{array}{l}\text { http://www.ncbi.nlm.nih.gov/pubmed/ } \\
16297800\end{array}$ \\
\hline Vitrification of vascular grafts & $\begin{array}{l}\text { http://www.ncbi.nlm.nih.gov/pubmed/ } \\
10700144\end{array}$ \\
\hline New technologies to permit rapid uniform heating & $\begin{array}{l}\text { http://www.sciencedirect.com/science/ } \\
\text { article/pii/S0011224013002289 }\end{array}$ \\
\hline $\begin{array}{l}\text { Development of new devices for thermal imaging to study ice } \\
\text { formation and understand/manipulate mechanisms }\end{array}$ & $\begin{array}{l}\text { http://www.ncbi.nlm.nih.gov/pubmed/ } \\
23993920\end{array}$ \\
\hline
\end{tabular}

transient recruitment of MSCs within the kidney with minimal cellular incorporation into the regenerating tubules [86, 135]. Based on this observation, it has been suggested that MSCs may provide a paracrine support to kidney repair [84]. This concept is supported by other studies involving intravenous treatment with MSCCM. In one study, capillary density and cardiac function were both improved following IV administration of human ESC-derived MSC-CM following myocardial infarction (MI) in a mouse model of myocardial $\mathrm{I} / \mathrm{R}$ injury [138]. In another study utilizing a pig model of MI, human MSC-CM administered IV was shown to increase capillary density and preserve cardiac function, likely by increasing myocardial perfusion [139, 140].

Consistent with the above reports, $\mathrm{Bi}$ et al. (2008) demonstrated that administration of MSC-CM may mimic the beneficial effects of the stem cell therapy, indicating that engraftment of MSCs in the renal
Table 4 New approaches for extending organ preservation

\begin{tabular}{|c|c|}
\hline Approach & Potential outcome \\
\hline Targeting gene regulatory pathways & Accessing and activating conserved genes for cold tolerance \\
\hline Proteomic technology & $\begin{array}{l}\text { Identification of key proteins related to cellular adaptation to } \mathrm{I} / \mathrm{R} \\
\text { injury }\end{array}$ \\
\hline Epigenetic mechanisms & May allow for anoxia tolerance as well as metabolic suppression \\
\hline Gene therapy & Transfection of IL-10 to improve key parameters in lung transplant \\
\hline \multicolumn{2}{|c|}{ Mesenchymal stem cells (MSCs) and organ preservation } \\
\hline Approach & Potential outcome \\
\hline MSC paracrine activity & $\begin{array}{l}\text { Secreted bioactive factors suppress the local immune system, } \\
\text { inhibit fibrosis and apoptosis, enhance angiogenesis, and } \\
\text { stimulate mitosis and differentiation of tissue-intrinsic } \\
\text { reparative or stem cells }\end{array}$ \\
\hline MSC engraftment potential & $\begin{array}{l}\text { Cells can support organ engraftment and capable } \\
\text { of tissue engineering }\end{array}$ \\
\hline MSC migratory potential & $\begin{array}{l}\text { MSCs may "target" sites of injury; potent chemokine } \\
\text { secretion recruits host MSCs and pericytes toward } \\
\text { sites of injury }\end{array}$ \\
\hline \multicolumn{2}{|l|}{ Novel trophic factor for I/R injury } \\
\hline Approach & Potential outcome \\
\hline Trophic factor cocktails & $\begin{array}{l}\text { Recombinant growth factors combined with hypothermic } \\
\text { preservation solutions for enhance tolerance to I/R injury }\end{array}$ \\
\hline MSC microvesicles & $\begin{array}{l}\text { Regenerative effect through transfer of RNA and provision of ATP; } \\
\text { induce prosurvival genes and down regulate proapoptotic genes }\end{array}$ \\
\hline MSC conditioned media & Exploitation of MSC paracrine influence on healing and engraftment \\
\hline $\begin{array}{l}\text { Conditioned media from novel cell } \\
\text { types }\end{array}$ & $\begin{array}{l}\text { Fetal liver stem cell (hepatic and hematopoietic) trophic factors for } \\
\text { liver transplant }\end{array}$ \\
\hline
\end{tabular}


tubules is not necessary, and Bruno et al. (2009) reported that intravenous administration of MVs derived from human MSCs has the same efficacy of MSCs on the functional and morphological recovery of glycerolinduced AKI in severe combined immunodeficient mice $[141,142]$.

Other novel sources of trophic factors to assist in organ repair/recovery following I/R injury are also now being investigated. Ongoing work by Petrenko focusing on fetal liver stem cells (both hepatic and hematopoietic) has yielded trophic factor "cocktails" which can be utilized as cell-free extracts. Petrenko has previously shown significant therapeutic effects of these trophic factors (TFs) on models of acute toxic hepatitis, experimental cirrhosis, chronic alcohol poisoning, solid tumor progression, and wound healing. Most recently, utilizing a non-hepatic source of mesenchymal stromal cellderived cell-free fetal-specific factors, Petrenko was able to demonstrate that supplementation of preservation solutions with such factors modulated redox-dependent processes and led to strengthening of cell adaptive responses to stress against $\mathrm{I} / \mathrm{R}$ injury. These results indicate the potential for TF derived from adult stem/progenitor cells and or conditioned culture media may be useful in reducing organ I/R injury [143].

The protective effect of MSC trophic factors seems to be supported by numerous studies; however, their specific mechanism(s) of action still remain unclear. These protective effects have been referred to as "survival factors" in cell culture studies and are often associated with antiapoptotic effects, protection against mitochondrial injury, and overall enhanced cell growth $[144,145]$. One potential mechanism is modulation of ERK1/2, p38 MAPK, and HO-1 signaling pathways during hypothermia and rewarming. While preliminary, these studies have demonstrated that modulating these pathways is correlated with reduced graft injury and improved long-term viability [126]. These trophic factors also seem to affect chemokine production and therefore leukocyte/pericyte recruitment, and modulation of these signaling pathways through hypothermic storage has been described [146]; however, means to exploit this favorably under clinical storage conditions are yet to be described [144].

\section{Conclusion}

The global need for optimized technologies for organ preservation is undeniable. As technologies have advanced allowing more complicated surgical procedures and expanding both potentially transplantable organs and recipients, the ability to maintain organs in a viable state throughout the process becomes a critical link in the chain that must be strengthened. Over the last several decades, there have been many advances coinciding with the renewed emphasis on organ preservation, many highlighted in the recent Road Map Report developed by the Organ Preservation Alliance (http://www. organpreservationalliance.org/roadmap).

While this review presented some compelling new avenues (see Tables 1, 2, 3, and 4), several other areas of investigation are also key to solving the global organ preservation problem, including advances in ex vivo perfusion, which in particular for lungs holds the potential to increase the number of transplantable organs and can serve as a platform for many of the novel biological interventions such as trophic factors, cells and gene therapies for all solid organs [75••].

Persufflation in organ preservation is another potential advancement which can allow for enhanced oxygenation during organ preservation for kidney, heart, pancreas, and liver, resulting in improved organ viability. Persufflation or the flow of hypothermic humidified oxygen gas through the vasculature of organs has been shown to be effective in oxygenating and preserving as well as recondition a variety of organs including kidneys, livers, hearts, and pancreata from expanded criteria donors in a variety of small and large animal models with excellent outcomes [75••, 147].

While the areas of research presented here as well as the existing number of pharmacological agents and therapeutic strategies have been shown to ameliorate different aspects of $\mathrm{I} / \mathrm{R}$ and organ preservation, the holistic approach which must be taken to ensure success can be complex and challenging.

\section{Compliance with Ethical Standards}

Conflict of Interest Erik J. Woods is employed by Cook Regentec. Steven F. Mullen is employed by Cook Regentec.

Human and Animal Rights and Informed Consent This article does not contain any studies with human or animal subjects performed by any of the authors.

\section{References}

Papers of particular interest, published recently, have been highlighted as:

- Of importance

•. Of major importance

1. Brockmann JG, Vaidya A, Reddy S, Friend PJ. Retrieval of abdominal organs for transplantation. Br J Surg. 2006;93(2):133-46.

2. Watson CJ, Dark JH. Organ transplantation: historical perspective and current practice. Br J Anaesth. 2012;108 Suppl 1:i29-42.

3. Taylor, M. J. Biology of cell survival in the cold: the basis for biopreservation of tissues and organs. Advances in Biopreservation. J. G. a. B. Baust, J.M. Boca Raton, Taylor and Francis Group: 15-62, 2007.

4. Kalogeris T, Baines CP, Krenz M, Korthuis RJ. Cell biology of ischemia/reperfusion injury. Int Rev Cell Mol Biol. 2012;298: 
229-317. This review provides a thorough description of the mechanisms for cell damage due to ischemia and reperfusion.

5. Belzer FO, Southard JH. Principles of solid-organ preservation by cold storage. Transplantation. 1988;45:673-6.

6. Finger EB. Organ preservation. 2015. http://emedicine.medscape. com/article/431140-overview. Accessed Dec 152015.

7. Dare AJ, Logan A, Prime TA, Rogatti S, Goddard M, Bolton E, et al. Mitochondrial-targeted anti-oxidant MitoQ decreases ischemia-reperfusion injury in a murine syngeneic heart transplant model. J Heart Lung Transplant. 2015;34:1471-80.

8. Simonson MS, Dunn MJ. Endothelins: a family of regulatory peptides. Stat-off-the-art Lect Hypertens. 1991;17:856-63.

9. Wilhelm SM, Simonson MS, Robinson AV, Stowe NT, Schulak JA. Cold ischemia induces endothelin gene upregulation in the preserved kidney. J Surg Res. 1999;85:101-8.

10. Soughar JH, Senzig KA, Belzer RO. Eeects of hypothermia on canine kidney mitochondria. Cryobiology. 1980;17:148-53.

11. Belzer FO. Evaluation of preservation of the intra-abdominal organs. Transplant Proc. 1993;25:2527-30.

12. Koyama I, Bulkley GB, Williams GM, Im MJ. The role of oxygen free radicals in mediating the reperfusion injry of cold-preserved ischemic kidneys. Transplantation. 1985;40:590-5.

13. Clavien PA, AHarvey PR, Strasberg SM. Preservation and reperfusion injuries in liver allografts. An overview and synthesis of current studies. Transplantation. 1992;53:957-78.

14. Colletti LM, Burtch GD, Remick DG, Kunkel SL, Strieter RM, Guice KS. The production of tumor necrosis factor alpha and the development of a pulmonary capillary injury following hepatic ischemia/reperfusion. Transplantation. 1990;49:268-72.

15. Strüber M, Harringer W, Ernst M, Morschheuser T, Hein M, Bund M. Inhaled nitric oxide as a prophylactic treatment against reperfusion injury of the lung. Thorac Cardiovasc Surg. 1999;47:17982.

16. Karlsson JO, Toner M. Long-term storage of tissues by cryopreservation: critical issues. Biomaterials. 1996;17:243-56.

17. Mazur P. Principles of cryobiology. In: Fuller BJ, Lane N, Benson EE, editors. Life in the Frozen State. Boca Raton: CRC Press; 2004. p. 3-65.

18. Polge $\mathrm{C}$ et al. Revival of spermatozoa after vitrification and dehydration at low temperatures. Nature. 1949;164:666.

19. Fuller BJ. Cryoprotectants: the essential antifreezes to protect life in the frozen state. Cryo-Letters. 2004;25:375-88.

20. Acker JP. The use of intracellular protectants in cell biopreservation. In: Baust JG, Baust JM, editors. Advances in Biopreservation. Boca Raton: Taylor and Francis; 2007. p. 299320 .

21. Lovelock JE. The mechanism of the protective action of glycerol against haemolysis by freezing and thawing. Biochim Biophys Acta. 1953;11:28-36.

22. Meryman HT. The exceeding of a minimum tolerable cell volume in hypertonic suspensions as a cause of freezing injury. In: Wolstenholme GEW, O'Connor M, editors. The Frozen Cell. London: J and A Churchill; 1970. p. 51-64.

23. Arakawa T, Timasheff SN. Mechanism of poly(ethylene glycol) interaction with proteins. Biochemistry. 1985;24:6756-62.

24. Arakawa T, Timasheff SN. The stabilization of proteins by osmolytes. Biophys J. 1985;47:411-4.

25. Mazur P, Leibo SP, Chu EH. A two-factor hypothesis of freezing injury. Evidence from Chinese hamster tissue-culture cells. Exp Cell Res. 1972;71:345-55.

26. Ashwood-Smith MJ, Morris GW, Fowler R, Appleton TC, Ashorn R. Physical factors are involved in the destruction of embryos and oocytes during freezing and thawing procedures. Hum Reprod. 1988;3:795-802.

27. Hunt CJ, Taylor MJ, Pegg DE. Freeze-substitution and isothermal freeze-fixation studies to elucidate the pattern of ice formation in smooth muscle at $252 \mathrm{~K}$ ( -21 degrees C). J Microsc; $125(\mathrm{Pt} 2)$ : 177-186.

28. Taylor MJ, Pegg DE. The effect of ice formation on the function of smooth muscle tissue stored at -21 or -60 degrees C. Cryobiology. 1983;20:36-40.

29. Farrant J, Morris GJ. Thermal shock and dilution shock as the causes of freezing injury. Cryobiology. 1973;10:134 40.

30. Lovelock JE. The haemolysis of human red blood cells by freezing and thawing. Biochim Biophys Acta. 1953;10:414-26.

31. Levitt JA. sulfhydryl-disulfide hypothesis of frost injury and resistance in plants. J Theor Biol 196;23:355-391.

32. Truskey GA, Yuan F, Katz DF. (2004). Transport phenomena in biological systems, Pearson Education, Inc.

33. Farrant J. Mechanism of cell damage during freezing and thawing and its prevention. Nature. 1965;205:1284-7.

34. Elford BC. Functional recovery of smooth muscle after exposure to dimethyl sulfoxide and low temperatures. Cryobiology. 1970;7: 148-53.

35. Farrant J, Walter CA, Lee H, McGann LE. Use of two-step cooling procedures to examine factors influencing cell survival following freezing and thawing. Cryobiology. 1977;14:273-86.

36. Pegg DE. Ice crystals in tissues and organs. In: Pegg DE, Karow AMJ, editors. The Biophysics of Organ Cryopreservation. New York: Plenum Press; 1987. p. 117-36.

37. Pegg DE. Mechanisms of freezing damage. In: Bowler K, Fuller BJ, editors. Temperature and Animal Cells. Cambridge: The company of biologists, Ltd; 1987. p. 363-78.

38. Lakey JR, Helms LE, Moser G, Lix B, Slupsky CM, Rebeyka IM, et al. Dynamics of cryoprotectant permeation in porcine heart valve leaflets. Cell Transplant. 2003;12(2):123-8.

39. Abazari A, Elliott JA, McGann LE, Thompson RB. MR spectroscopy measurement of the diffusion of dimethyl sulfoxide in articular cartilage and comparison to theoretical predictions. Osteoarthr Cartil. 2012;20:1004-10.

40. Fuller BJ, Busza AL, Proctor E. Studies on cryoprotectant equilibration in the intact rat liver using nuclear magnetic resonance spectroscopy: a noninvasive method to assess distribution of dimethyl sulfoxide in tissues. Cryobiology. 1989;26(2):112-8.

41. Rabin Y, Steif PS. Thermal stress modeling of the freezing of biological tissue. Adv Heat Mass Transf Biotechnol. 1999;44: 183-7.

42. Rabin Y, Steif PS. Solid mechanics aspects of cryobiology. In: Fuller BJ, Lane N, Benson EE, editors. Life in the Frozen State. Boca Raton: CRC Press; 2004. p. 359-81.

43. Rall WF, Meyer TK. Zona fracture damage and its avoidance during the cryopreservation of mammalian embryos. Theriogenology. 1989;31(3):683-92.

44. Pegg DE, Wusteman MC, Boylan S. Fractures in cryopreserved elastic arteries. Cryobiology. 1997;34:183-92.

45. Wusteman M, Robinson M, Pegg D. Vitrification of large tissues with dielectric warming: biological problems and some approaches to their solution. Cryobiology. 2004;48:179-89.

46. Ting AY, Yeoman RR, Campos JR, Lawson MS, Mullen SF, Fahy $\mathrm{GM}$, et al. Morphological and functional preservation of pre-antral follicles after vitrification of macaque ovarian tissue in a closed system. Hum Reprod. 2013;25:1267-79.

47. Rubinsky B, Lee CY, Bastacky J, Onik G. The process of freezing and the mechanism of damage during hepatic cryosurgery. Cryobiology. 1990;27(1):85-97.

48. Fahy GM, MacFarlane DR, Angell CA, Meryman HT. Vitrification as an approach to cryopreservation. Cryobiology. 1984;21:407-26.

49. Stiles W. On the cause of cold death of plants. Protoplasma. 1930;9:459-68.

50. Luyet B. The vitrification of organic colloids and of protoplasm. Biodynamica. 1937;1:1-14. 
51. Luyet BJ, Gehenio PM. Life and death at low temperatures. Missouri: Normandy; 1940.

52. Lebermann J, Dietl J, Vanderzwalmen P, Tucker MJ. Recent developments in human oocyte, embryo and blastocyst vitrification: where are we now? Reprod Biomed Online. 2003;7:623-33.

53. Fahy GM, MacFarlane DR, Angell CA. Recent progress toward vitrification of kidneys. Cryobiology. 1982;19:668-9.

54. Fahy GM. Vitrification as an approach to organ cryopreservation: past, present, and future. In: Smit Sibinga CT, Das PC, Meryman HT, editors. Cryopreservation and low temperature biology in blood transfusion. Boston: Kluwer; 1990. p. 255-68.

55. Fahy GM, Rall WF. Vitrification: an overview. In: Tucker MJ, Liebermann J, editors. Vitrification in Assisted Reproduction. London: Informa Healthcare; 2007. p. 1-20.

56. Mullen SF, Fahy GM. Fundamental aspects of vitrification as a method of reproductive cell, tissue, and organ cryopreservation. In: Donnez J, Kim SS, editors. Principles and Practice of Fertility Preservation. Cambridge: Cambridge University Press; 2011. p. 145-63.

57. Pegg DE, Jacobsen IA, Diaper MP, Foreman J. Optimization of a vehicle solution for the introduction and removal of glycerol with rabbit kidneys. Cryobiology. 1986;23(1):53-63.

58. Fahy GM, Lilley TH, Linsdell H, Douglas MS, Meryman HT. Cryoprotectant toxicity and cryoprotectant toxicity reduction: in search of molecular mechanisms. Cryobiology. 1990;27(3):24768.

59. Kasai M, Nishimori M, Zhu SE, Sakurai T, Machida T. Survival of mouse morulae vitrified in an ethylene glycol-based solution after exposure to the solution at various temperatures. Biol Reprod. 1992;47:1134-9.

60. Wowk B, Leitl E, Rasch CM, Mesbah-Karimi N, Harris SB, Fahy GM. Vitrification enhancement by synthetic ice blocking agents. Cryobiology. 2000;40:228-36.

61. Wowk B, Fahy GM. Inhibition of bacterial ice nucleation by polyglycerol polymers. Cryobiology. 2002;44:14-23.

62. Fahy GM, Wowk B, Wu J, Paynter S. Improved vitrification solutions based on the predictability of vitrification solution toxicity. Cryobiology. 2004;48:22-35.

63. Fahy, G. M. Advantageous carrier solution for vitrifiable concentrations of cryoprotectants, and compatible cryoprotectant mixtures. U.S. Patent 6,869,757; Issued March 22,2005, 2005.

64. Ali J, Shelton J. Development of vitrification solutions. In: Tucker MJ, Liebermann J, editors. Vitrification in Assisted Reproduction. London: Informa Healthcare; 2007. p. 45-63.

65. Mullen SF, Li M, Li Y, Chen ZJ, Critser JK. Human oocyte vitrification: the permeability of metaphase II oocytes to water and ethylene glycol and the appliance toward vitrification. Fertil Steril. 2008;89:1812-25.

66. Fahy GM. Cryoprotectant toxicity neutralization. Cryobiology. 2010;60(3 Suppl):S45-53.

67. Fahy GM, Wowk B, Wu J, Phan J, Rasch C, Chang A, et al. Cryopreservation of organs by vitrification: perspectives and recent advances. Cryobiology. 2004;48(2):157-78.

68.• Guibert EE, Petrenko AY, Balaban CL, Somov AY, Rodriguez JV, Fuller BJ. Organ preservation: current concepts and new strategies for the next decade. Transfus Med Hemother. 2011;38:125-42. This is an excellent review on the future of organ preservation and banking.

69. Storey KB, Storey JM. Natural freeze tolerance in exothermic vertebrates. Ann Rev Physiol. 1992;54:619-37.

70. Biggar KK, Storey KB. The emerging role of microRNAs in the molecular responses of metabolic rate depression. J Mol Cell Biol. 2011;3:167-75

71. Krivoruchko A, Storey KB. Epigenetics in anoxia tolerance: a role for histone deacetylases. Mol Cell Biochem. 2010;342:151-61.
72. Morin P, Storey KB. Mammalian hibernation: differential gene expression and novel application of genetic controls. Int J Dev Biol. 2009;53:433-42.

73. White D, Storey KB. Freeze-induced alterations of translatable mRNA populations in wood frog organs. Cryobiology. 1999;38: 353-62.

74. Storey KB. Strategies for exploration of freeze responsive gene expression: advances in vertebrate freeze tolerance. Cryobiology. 2004;48:134-45.

75.• Lewis JK, Bischof JC, Braslavsky I, Brockbank KGM, Fahy GM, Fuller BJ, et al. The grand challenges of organ banking: proceedings from the first global summit on complex tissue cryopreservation. Cryobiology. 2015. doi:10.1016/j.cryobiol.2015.12.001. These proceedings capture the problems and potential pathways to solutions for complex tissue preservation.

76. Edgardo E, Guiberta EE, Petrenko AY, Balabana CL, Somovb AY, Rodrigueza JV, et al. Organ preservation: current concepts and new strategies for the next decade. Transfus Med Hemother. 2011;38:125-42.

77. Hafez T, Fuller B: Applications: organ preservation for transplantation; in Baust JG (ed): Advances in Biopreservation. Owego, Cell Preservation Services, 2006, vol 9, pp 197-270.

78. Zhong Z, Ramshesh VK, Rehman H, Currin RT, Sridharan V, Theruvath TP, et al. Activation of the oxygen-sensing signal cascade prevents mitochondrial injury after mouse liver ischemiareperfusion. Am J Physiol Gastrointest Liver Physiol. 2008;295: G823-32.

79. Semenza GL. Surviving ischemia: adaptive responses mediated by hypoxia-inducible factor 1. J Clin Invest. 2000;106:809-11.

80. Strey CW, Gestrich J, Beckhaus T, Marquez-Pinilla RM, Oppermann E, Monch C, et al. Hypoxia and reoxygenation of primary human hepatocytes induce proteome changes of glucose metabolism, oxidative protection and peroxisomal function. Int $\mathrm{J}$ Molec Med. 2010;26:577-84.

81. Thirumala S, Goebel WS, Woods EJ. Manufacturing and banking of mesenchymal stem cells. Expert Opinions Biol Ther. 2013;13: 673-91.

82. Woods EJ, Pollok KE, Byers MA, Perry BC, Purtteman J, Heimfeld S, et al. Cord blood stem cell cryopreservation. Transfus Med Hemother. 2007;34:276-85.

83. Brooke G, Cook M, Blair C, Han R, Heazlewood C, Jones B, et al. Therapeutic applications of mesenchymal stromal cells. Semin Cell Dev Biol. 2007;18:846-58.

84. Caplan AI, Dennis JE. Mesenchymal stem cells as trophic mediators. J Cell Biochem. 2006;98:1076-84.

85. Burst VR, Gillis M, Putsch F, et al. Poor cell survival limits the beneficial impact of mesenchymal stem cell transplantation on acute kidney injury. Nephron Exp Nephrol. 2010;114:e107-16.

86. Togel F, Hu Z, Wiess K, et al. Administered mesenchymal setem cells protect against ischemic acute renal failure through differentiation-independent mechanisms. Am J Physiol Renal Physiol. 2005;289:F31-42.

87. Ankrum J, Karp JM. Mesenchymal stem cell therapy: two steps forward, onestep back. Trends Mol Med. 2010;16:203-9.

88. Herrera MB, Bussolati B, Bruno S, et al. Exogenous mesenchymal stem cellslocalize to the kidney by means of CD44 following acute tubular injury. Kidney Int. 2007;72:430-41.

89. Liu H, Liu S, Li Y, et al. The role of SDF-1-CXCR4/CXCR7 axis in thetherapeutic effects of hypoxia-preconditioned mesenchymal stem cells for renal ischemia/reperfusion injury. PLoS One. 2012;7, e34608.

90. Togel FE, Westenfelder C. Kidney protection and regeneration following acute injury: progress through stem cell therapy. Am J Kidney Dis. 2012;60:1012-22. 
91. Eggenhofer E, Benseler V, Kroemer A, et al. Mesenchymal stem cells are short-lived and do not migrate beyond the lungs after intravenous infusion. Front Immunol. 2012;3:297.

92. Souidia N, Stolka M, Seiferta M. Ischemia-reperfusion injury: beneficial effects of mesenchymal stromal cells. Curr Opin Organ Transpl. 2013;18:34-43. This paper describes the combination of cell therapy and organ transplant. A good review of the use MSCs.

93. Togel F, Zhang P, Hu Z, et al. VEGF is a mediator of the renoprotective effects of multipotent marrow stromal cells in acute kidney injury. J Cell Mol Med. 2009;13:2109-14.

94. Lee JW, Gupta N, Serikov V, et al. Potential application of mesenchymal stem cells in acute lung injury. Expert Opin Biol Ther. 2009;9:1259-70.

95. Birukova AA, Zagranichnaya T, Fu P, et al. Prostaglandins PGE(2) and PGI(2) promote endothelial barrier enhancement via PKA- and Epac1/Rap1-dependent Rac activation. Exp Cell Res. 2007;313:2504-20.

96. Fang X, Neyrinck AP, Matthay MA, et al. Allogeneic human mesenchymal stem cells restore epithelial protein permeability in cultured human alveolar type II cells by secretion of angiopoietin1. J Biol Chem. 2010;285:26211-22.

97. Poynter JA, Herrmann JL, Manukyan MC, et al. Intracoronary mesenchymal stem cells promote postischemic myocardial functional recovery, decrease inflammation, and reduce apoptosis via a signal transducer and activator of transcription 3 mechanism. J Am Coll Surg. 2011;213:253-60.

98. Sato T, Iso Y, Uyama T, et al. Coronary vein infusion of multipotent stromal cells from bone marrow preserves cardiac function in swine ischemic cardiomyopathy via enhanced neovascularization. Lab Invest. 2011;91:553-64.

99. Jarvinen L, Badri L, Wettlaufer S, et al. Lung resident mesenchymal stem cells isolated from human lung allografts inhibit $\mathrm{T}$ cell proliferation via a soluble mediator. J Immunol. 2008;181:438996.

100. Imberti B, Morigi M, Tomasoni S, et al. Insulin-like growth factor1 sustains stem cell mediated renal repair. J Am Soc Nephrol. 2007;18:2921-8.

101. Casiraghi F, Azzollini N, Cassis P, et al. Pretransplant infusion of mesenchymal stem cells prolongs the survival of a semiallogeneic heart transplant through the generation of regulatory $\mathrm{T}$ cells. $\mathrm{J}$ Immunol. 2008;181:3933-46.

102. Ge W, Jiang J, Baroja ML, et al. Infusion of mesenchymal stem cells and rapamycin synergize to attenuate alloimmune responses and promote cardiac allograft tolerance. Am J Transplant. 2009;9: 1760-72.

103. Kim J, Hematti P. Mesenchymal stem cell-educated macrophages: a novel type of alternatively activated macrophages. Exp Hematol. 2009;37:1445-53.

104. Maggini J, Mirkin G, Bognanni I, et al. Mouse bone marrowderived mesenchymal stromal cells turn activated macrophages into a regulatory-like profile. PLoS One. 2010;5, e9252.

105. Wise AF, Ricardo SD. Mesenchymal stem cells in kidney inflammation and repair. Nephrology (Carlton). 2012;17:1-10.

106. Cao H, Qian H, Xu W, et al. Mesenchymal stem cells derived from human umbilical cord ameliorate ischemia/reperfusion-induced acute renal failure in rats. Biotechnol Lett. 2010;32:725-32.

107. Chen YT, Sun CK, Lin YC, et al. Adipose-derived mesenchymal stem cell protects kidneys against ischemia-reperfusion injury through suppressing oxidative stress and inflammatory reaction. J Transl Med. 2011;9:51

108. Furuichi K, Shintani H, Sakai Y, et al. Effects of adipose-derived mesenchymal cells on ischemia-reperfusion injury in kidney. Clin Exp Nephrol. 2012;16:679-89.
109. Donizetti-Oliveira C, Semedo P, Burgos-Silva MT, et al. Adipose tissue derived stem cell treatment prevents renal disease progression. Cell Transplant. 2012;21:1727-41.

110. Alfarano C, Roubeix C, Chaaya R, et al. Intraparenchymal injection of bone marrow mesenchymal stem cells reduces kidney fibrosis after ischemia-reperfusion in cyclosporineimmunosuppressed rats. Cell Transplant. 2012;21(9):2009-19.

111. Chen Y, Qian H, Zhu W, et al. Hepatocyte growth factor modification promotes the amelioration effects of human umbilical cord mesenchymal stem cells on rat acute kidney injury. Stem Cells Dev. 2011;20:103-13.

112. Zhen-Qiang F, Bing-Wei Y, Yong-Liang L, et al. Localized expression of human BMP-7 by BM-MSCs enhances renal repair in an in vivo model of ischemia-reperfusion injury. Genes Cells. 2012;17: 53-64.

113. La Manna G, Bianchi F, Cappuccilli M, et al. Mesenchymal stem cells in renal function recovery after acute kidney injury: use of a differentiating agent in a rat model. Cell Transplant. 2011;20: 1193-208.

114. Tian H, Lu Y, Shah SP, et al. 14S,21R-dihydroxydocosahexaenoic acid treatment enhances mesenchymal stem cell amelioration of renal ischemia/reperfusion injury. Stem Cells Dev. 2012;21:1187-99.

115. Altun B, Yilmaz R, Aki T, et al. Use of mesenchymal stem cells and darbepoetin improve ischemia-induced acute kidney injury outcomes. Am J Nephrol. 2012;35:531-9.

116. Hara Y, Stolk M, Ringe J, et al. In vivo effect of bone marrowderived mesenchymal stem cells in a rat kidney transplantation model with prolonged cold ischemia. Transpl Int. 2011;24:1112 23.

117. Franquesa M, Herrero E, Torras J, et al. Mesenchymal stem cell therapy prevents interstitial fibrosis and tubular atrophy in a rat kidney allograft model. Stem Cells Dev. 2012;21:3125-35.

118. Song L, Xu J, Qu J, et al. A therapeutic role for mesenchymal stem cells in acute lung injury independent of hypoxia-induced mitogenic factor. J Cell Mol Med. 2012;16:376-85.

119. Xu J, Woods CR, Mora AL, et al. Prevention of endotoxininduced systemic response by bone marrow-derived mesenchymal stem cells in mice. Am J Physiol Lung Cell Mol Physiol. 2007;293:L131-41.

120. Gupta N, Su X, Popov B, et al. Intrapulmonary delivery of bone marrow derived mesenchymal stem cells improves survival and attenuates endotoxininduced acute lung injury in mice. J Immunol. 2007; 179:1855-63.

121. Li J, Li D, Liu X, et al. Human umbilical cord mesenchymal stem cells reduce systemic inflammation and attenuate LPS-induced acute lung injury in rats. J Inflamm (Lond). 2012;9:33.

122. Matthay MA, Thompson BT, Read EJ, et al. Therapeutic potential of mesenchymal stem cells for severe acute lung injury. Chest. 2010;138:965-72.

123. Manning E, Pham S, Li S, et al. Interleukin-10 delivery via mesenchymal stem cells: a novel gene therapy approach to prevent lung ischemia-reperfusion injury. Hum Gene Ther. 2010;21:71327.

124. Tan J, Wu W, Xu X, et al. Induction therapy with autologous mesenchymal stem cells in living-related kidney transplants: a randomized controlled trial. JAMA. 2012;307:1169-77.

125. Reinders MEJ, De Fijter JW, Roelofs H, Bajema IM, De Vries $\mathrm{DK}$, Schaapherder AF, et al. Autologous bone marrow-derived mesenchymal stromal cells for the treatment of allograft rejection after renal transplantation: results of a Phase I study. Stem Cells Transl Med. 2013;2:107-11.

126. McNaulty JF, Reid TW, Waller KR, Murphy CJ. Successful sixday kidney preservation using trophic factor supplemented media and simple cold storage. Am J Transplant. 2002;2:712-8. 
127. Gan BS, MacCannell KL, Hollenberg MD. Epidermal growth factor-urogastrone causes vasodilatation in the anesthetized dog. J Clin Invest. 1987;80:199-206.

128. Petrinec D, Reilly JM, Sicard GA, et al. Insulin-like growth factor-I attenuates delayed graft function in a canine renal autotransplantation model. Surgery. 1996;120:221-5.

129. Maestri M, Dafoe DC, Adams GA, et al. Insulin-like growth factor-I ameliorates delayed kidney graft function and the acute nephrotoxic effects of cyclosporine. Transplantation. 1997;64: 185-90.

130. Schwab IR, Dries D, Cullor J, et al. Corneal storage medium preservation with defensins. Cornea. 1992;11:370-5.

131. Chan EY, Stang SL, Bottorff DA, Stone JC. Hypothermic stress leads to activation of Ras-Erk signaling. J Clin Invest. 1999;103: 1337-44.

132. Arai S, Mochida S, Ohno A, et al. Decreased expression of receptors for vascular endothelial growth factor and sinusoidal endothelial cell damage in cold-preserved rat livers. Transplant Proc. 1999;31:2668-72.

133. Wagerle LC, Kim SJ, Russo P. Protein tyrosine kinase signaling in cold stimulated contraction of newborn lamb cerebral arteries. Am J Physiol. 1996;270:H645-50.

134. Dahdah NS, Russo P, Wagerle LC. Phosphorylation in coronary artery cold-induced contraction in the newborn lamb. Cryobiology. 2001;42:40-8.

135. Gatti S, Bruno S, Deregibus MC, Sordi A, Cantaluppi V, Tetta C, et al. Microvesicles derived from human adult mesenchymal stem cells protect against ischaemia-reprerfusion-induced acute and chronic kidney injury. Nephrol Dial Transplant. 2011;26:1474-83.

136. Choi S, Park M, Kim J. Mesenchumal stem cell thjerapy for chronic renal failure. Expert Opin Biol Ther. 2010;10:1217-26.

137. Bruno S, Grange C, Collino F, et al. Microvesicles derived from mesenchymal stem cells enhance survival in a lethal model of acute kidney injury. PLoS One. 2012;7, e33115.
138. Lai RC, Arslan F, Lee MM, et al. Exosome secreted by MSC reduces myocardial ischemia/reperfusion injury. Stem Cell Res. 2010;4:214-22.

139. Timmers L, Lim SK, Hoefer IE, et al. Human mesenchymal stem cell-conditioned medium improves cardiac function following myocardial infarction. Stem Cell Res. 2011;6:206-14.

140. Nguyen BK, Maltais S, Perrault LP, et al. Improved function and myocardial repair of infarcted heart by intracoronary injection of mesenchymal stem cell derived growth factors. J Cardiovasc Transl Res. 2010;3:547-58.

141. Bi B, Guo J, Marlier A, et al. Erythropoietin expands a stromal cell population that can mediate renoprotection. Am J Physiol Ren Physiol. 2008;295:F1017-22.

142. Bruno S, Grange C, Deregibus MC, et al. Mesenchymal stem cellderived microvesicles protect against acute tubular injury. J Am Soc Nephrol. 2009;20:1053-67.

143. Petrenko A, Cherkashina D, Semenchenko OA, Rogulskaya E. Cold storage of isolated hepatocytes: effect of trophic factors in preservation solution. Cryobiology. 2015;71:562.

144. McNaulty JF. Hypothermic organ preservation by static storage methods: current status and view to the future. Cryobiology. 2010;60:S13-9.

145. Kwon YS, Foley JD, Russell P, McAnulty JF, Murphy CJ. Prevention of cold ischemia/rewarming-induced ERK 1/2, p38 kinase and HO-1 activation by trophic factor supplementation of UW solution. Cryobiology. 2008;57:72-4.

146. Andrabi SA, Dawson TM, Dawson VL. Mitochondrial and nuclear cross talk in cell death: parthanatos. Ann NY Acad Sci. 2008;1147:233-41.

147. Suszynski TM, Rizzari MD, Scott III WE, Eckman PM, Fonger JD, John R, et al. Persufflation (gaseous oxygen perfusion) as a method of heart preservation. J Cardiothorac Surg. 2013;8:105. 